\title{
Qualidade de sementes de feijão-azuki dessecadas com saflufenacil e submetidas ao armazenamento
}

\author{
Cássio J. Tavares ${ }^{1}$, Alana C. F. Araújo ${ }^{2}$, Adriano Jakelaitis ${ }^{2}$, \\ Osvaldo Resende ${ }^{2}$, Juliana de F. Sales ${ }^{2} \&$ Marco A. M. Freitas ${ }^{1}$ \\ ${ }^{1}$ Instituto Federal Goiano - Câmpus Posse. Posse, GO. E-mail: cassio.tavares@ifgoiano.edu.br (Autor correspondente); marco.freitas@ifgoiano.edu.br \\ ${ }^{2}$ Instituto Federal Goiano - Câmpus Rio Verde. Rio Verde, GO. E-mail:alanashego@hotmail.com; ajakelaitis@yahoo.com.br; osvresende@yahoo.com.br; \\ julianacefetrv@yahoo.com.br
}

\author{
Palavras-chave: \\ Vigna angularis Willd. \\ vigor \\ herbicidas \\ patógenos \\ ambiente natural
}

\begin{abstract}
R E S U M O
Objetivou-se, nesta pesquisa, avaliar o efeito do uso do herbicida saflufenacil como dessecante em pré-colheita e do armazenamento sobre a qualidade fisiológica e sanitária de sementes de feijão-azuki. Foram testadas seis doses do herbicida saflufenacil $(0,50,75$, 100, 150 e $200 \mathrm{~g}$ a.i. ha ${ }^{-1}$ ) e duas épocas de avaliação da qualidade das sementes: colheita e seis meses após a colheita. A aplicação do dessecante ocorreu na maturidade fisiológica do feijoeiro azuki e as sementes colhidas foram armazenadas em sacos de papel (Kraft) em ambiente natural, a $25,4 \pm 3{ }^{\circ} \mathrm{C}$ de temperatura e $67,3 \pm 3 \%$ umidade relativa. $\mathrm{O}$ saflufenacil pode ser utilizado até a dose de $65 \mathrm{~g}$ a.i. $\mathrm{ha}^{-1}$ sem prejudicar a qualidade fisiológica das sementes. $\mathrm{O}$ armazenamento provocou queda na percentagem de germinação, aumento no número de plântulas anormais e redução no tamanho e da massa seca das plântulas. A dessecação em pré-colheita e o armazenamento reduzem a infestação Cladosporium, Fusarium, e Rizhopus nas sementes de feijão-azuki.
\end{abstract}

\section{Key words:}

Vigna angularis Willd.

vigor

herbicides

pathogens

natural environment

\section{Quality of azuki bean seeds desiccated with saflufenacil and submitted to storage}

\begin{abstract}
A B S T R A C T
The objective of this study was to evaluate the effect of using the herbicide saflufenacil desiccant pre-harvest and storage on the physiological and sanitary quality of azuki bean seeds. Six doses of saflufenacil herbicide $\left(0,50,75,100,150\right.$ and $200 \mathrm{~g}_{\text {a.i. }}$ ha $\left.^{-1}\right)$ were tested and two evaluation periods of seed quality: harvest and six months after harvest. The desiccant application occurred at physiological maturity of azuki bean and seeds were stored in paper bags (kraft) under natural conditions - $25.4 \pm 3{ }^{\circ} \mathrm{C}$ temperature and 67.3 $\pm 3 \%$ relative humidity. The saflufenacil may be used up to a dose of $65 \mathrm{~g}$ a.i. ha ${ }^{-1}$, without harming the physiological seed quality. The storage caused a drop in the percentage of germination, increase in the number of abnormal seedlings and reduction in size and dry mass of seedlings. Desiccation pre-harvest and storage reduces the infestation of Cladosporium, Fusarium and Rizhopus on the azuki bean seed.
\end{abstract}




\section{INTRODUÇÃo}

O feijão-azuki é produzido principalmente na Ásia e consumido na China, no Japão e na Coreia. No Brasil ainda não existem estatísticas precisas em relação ao número de produtores, produção ou área cultivada com esse tipo de feijão (Almeida et al., 2013).

A utilização de dessecantes para antecipação da colheita de sementes tem sido empregada nas culturas, sobretudo na soja (Toledo et al., 2014) e no feijão-comum (Franco et al., 2013) logo após atingirem a maturidade fisiológica buscando facilitar a colheita, diminuir injúrias mecânicas, ataque de pragas e microrganismos após o período de maturidade fisiológica (Toledo et al., 2014).

O conhecimento do produto e da dose de aplicação evita perdas no rendimento e no vigor das plântulas (Toledo et al., 2014). O saflufenacil é um herbicida usado em pré-emergência, pré-plantio incorporado ou pós-emergência para o controle sobremaneira de plantas daninhas dicotiledôneas. Trata-se de uma molécula que age inibindo a enzima protoporfirinogênio oxidase (PROTOX) (Grossmann et al., 2011). Como dessecante na cultura da soja e do feijão-comum sua dosagem varia de 49-98 $\mathrm{g}^{\text {ia ha }}{ }^{-1}$.

O processo de deterioração após a colheita é inevitável mas pode ser retardado dependendo das condições de armazenamento das sementes (Cardoso et al., 2012). Em geral, para a cultura do feijão o armazenamento é realizado em condições ambientais não controladas sendo a temperatura, a umidade relativa do ar tal bem como os fatores inerentes à própria semente, como o teor de água, determinantes da longevidade dessas sementes (Silva et al., 2014).

Diante do exposto objetivou-se, neste trabalho, avaliar o efeito de doses do herbicida saflufenacil e do armazenamento sobre a qualidade fisiológica e sanitária de sementes de feijãoazuki.

\section{MATERIAL e Métodos}

A pesquisa foi conduzida no IF Goiano, Campus Rio Verde, Rio Verde, GO. A análise do solo (Latossolo Vermelho distroférrico) apresentou, na profundidade de 0 a $20 \mathrm{~cm}$ : $\mathrm{pH}$ $\left(\mathrm{CaCl}_{2}\right)$ de 5,2; P de $11 \mathrm{mg} \mathrm{dm}^{-3}$; $\mathrm{K}_{\text {de }} 246 \mathrm{mg} \mathrm{dm}^{-3}$; Ca de 5,77 $\mathrm{cmol}_{\mathrm{c}} \mathrm{dm}^{-3} ; \mathrm{Mg}$ de $1,63 \mathrm{cmol}_{\mathrm{c}} \mathrm{dm}^{-3} ; \mathrm{Al} \mathrm{de} 0,03 \mathrm{cmol}_{\mathrm{c}} \mathrm{dm}^{-3} ; \mathrm{V} \%$ de 64,6 e textura de 46, 10 e $44 \mathrm{dag}^{\mathrm{k} \mathrm{g}^{-1}}$ de argila, silte e areia, respectivamente. Os dados climatológicos durante a condução do experimento se encontram na Figura 1.

Foi adotado o delineamento experimental em blocos ao acaso, em esquema de parcelas subdivididas. Nas parcelas foram testadas seis doses do herbicida saflufenacil $(0,50,75$, 100, 150 e $200 \mathrm{~g}$ i.a ha-1) e nas subparcelas as duas épocas de avaliação da qualidade das sementes: colheita (sem armazenamento das sementes) e após armazenamento por seis meses (6 MA) com quatro repetições.

Cada unidade experimental foi de $20 \mathrm{~m}^{2}$, constituída por oito fileiras de feijão, com cinco metros de comprimento e com a área útil constituída pelas quatro linhas centrais descartandose as bordaduras e também $0,5 \mathrm{~m}$ de cada extremidade.

O preparo do solo foi efetuado por meio de uma aração e duas gradagens e a semeadura semimecanizada do feijão foi

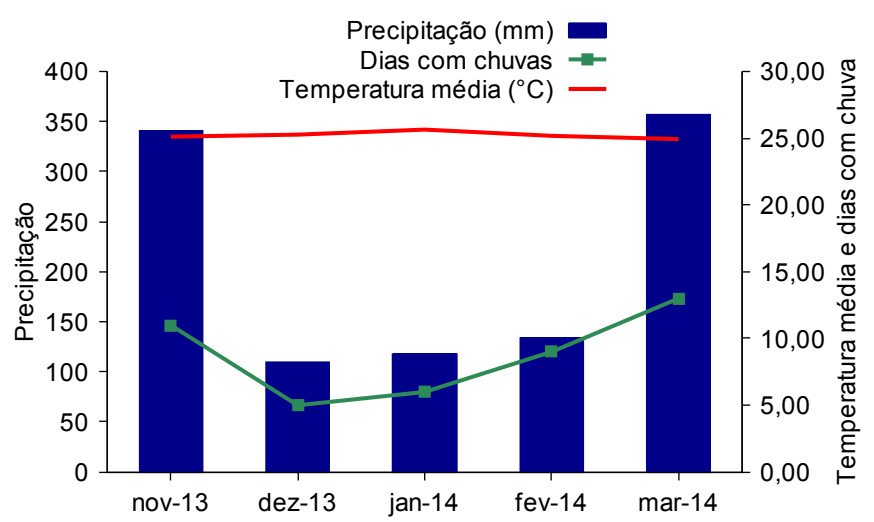

Figura 1. Precipitação pluvial, temperatura média e número de dias com chuvas no período de novembro de 2013 a março de 2014, em Rio Verde, GO

realizada no dia 28 de novembro de 2013, com a população de 18 sementes por metro linear, profundidade de $4 \mathrm{~cm}$ e a adubação de base realizada no sulco de semeadura foi de $350 \mathrm{~kg} \mathrm{ha}^{-1} \mathrm{da}$ formulação 02-20-18 (N, $\left.\mathrm{P}_{2} \mathrm{O}_{5}, \mathrm{~K}_{2} \mathrm{O}\right)$. Após 25 dias foi realizada a adubação de cobertura com $60 \mathrm{~kg} \mathrm{ha}^{-1} \mathrm{de} \mathrm{N}$ na forma de ureia.

O controle de plantas daninhas foi realizado por meio de capinas manual até o fechamento do dossel da cultura. Como tratamento fitossanitário foi realizada aos 28 e 42 dias após a semeadura, a aplicação do fungicida piraclostrobina na dose de $0,075 \mathrm{~kg} \mathrm{ha}^{-1}$ e do inseticida thiamethoxan na dose de $0,060 \mathrm{~kg}$ $\mathrm{ha}^{-1}$, respectivamente. As plantas apresentaram bom padrão de desenvolvimento durante o ciclo de cultivo com características e rendimento esperados para esta espécie.

A aplicação dos dessecantes ocorreu aos 68 dias após a semeadura (DAS) ocasião da maturidade fisiológica, quando o feijoeiro apresentava uma vagem com coloração típicamente madura. Os tratamentos foram aspergidos com pulverizador costal pressurizado a $\mathrm{CO}_{2}$, contendo quatro pontas de pulverização modelo TT $110^{\circ} 03$, a pressão constante de 2,5 bar e volume de calda de $250 \mathrm{~L} \mathrm{ha}^{-1}$.

O feijoeiro foi colhido manualmente quando apresentava $12 \%$ de teor de água (b.u) seguindo as orientações de Almeida et al. (2013). Nos tratamentos em que ocorreu a aplicação do dessecante a colheita ocorreu aos seis dias após a aplicação e onde não ocorreu, onze dias após a aplicação. As sementes foram acondicionadas em sacos de papel tipo kraft e armazenadas em condições ambientes pelo período de seis de meses. A umidade relativa (UR) e a temperatura foram registradas por um "data logger" digital (precisão: 0,1 ${ }^{\circ} \mathrm{C} ; 5,0 \%$ UR) obtendo-se valores médios durante o período de temperatura $25,4 \pm 3{ }^{\circ} \mathrm{C}$ e UR $67,3 \pm 3 \%$.

A qualidade fisiológica e sanitária das sementes foi avaliada na colheita das sementes e após seis meses de armazenamento. Para estabelecer a qualidade fisiológica as sementes foram submetidas a limpeza por meio de catação manual e, se descartando as sementes visivelmente danificadas, foram selecionadas cinquenta sementes por unidade experimental as quais foram submetidas aos seguintes testes: teor de água, germinação, envelhecimento acelerado, emergência e índice de velocidade de emergência (IVE) (Brasil, 2009) e condutividade elétrica (Vieira \& Krzyzanowski, 1999). O método utilizado no teste de sanidade foi o do papel filtro ("blotter test") conforme descrito por Neergaard (1979). 
Os resultados foram submetidos à análise de variância pelo teste $\mathrm{F}$ e, quando significativos, submetidos à análise de regressão a 0,05 de significância.

\section{Resultados e Discussão}

A condutividade elétrica sofreu influência da interação das fontes de variação. O aumento nas doses de saflufenacil aumentou linearmente a condutividade elétrica das sementes
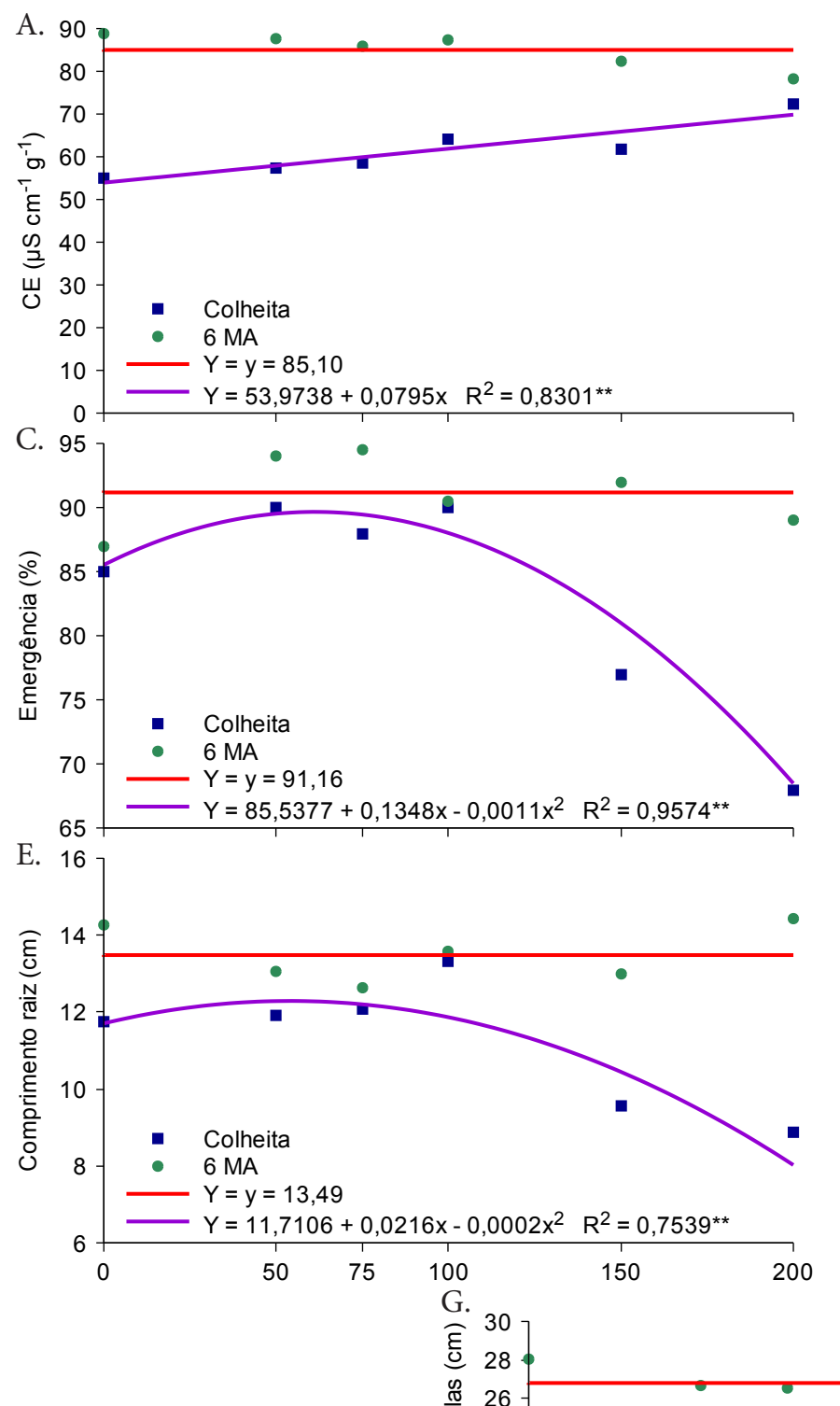

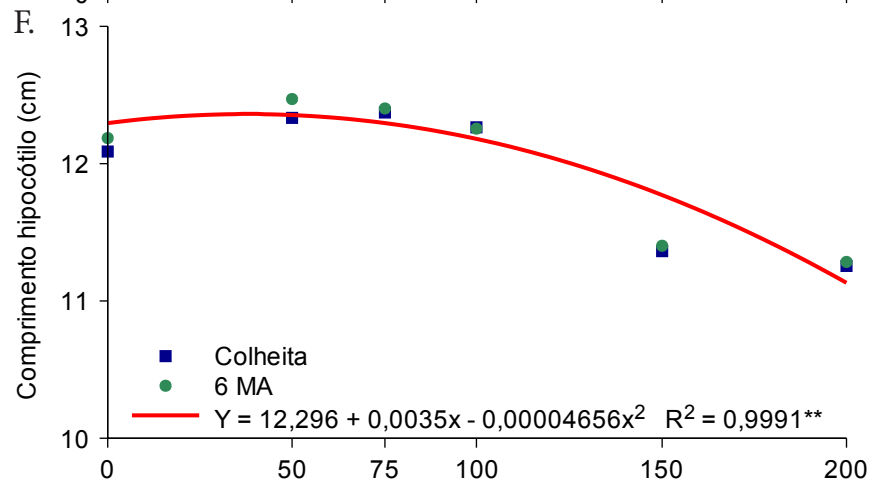

na avaliação realizada na colheita sendo que, após seis meses, esta variável não sofreu alteração pela aplicação do dessecante (Figura 2A).

As sementes armazenadas lixiviaram maiores quantidades de solutos independente da dose do herbicida (Figura 2A). Na ausência da aplicação de saflufenacil obteve-se menor valor de condutividade elétrica de sementes as quais foram, portanto, consideradas mais vigorosas. $\mathrm{O}$ aumento na liberação de eletrólitos das sementes após o período de armazenamento

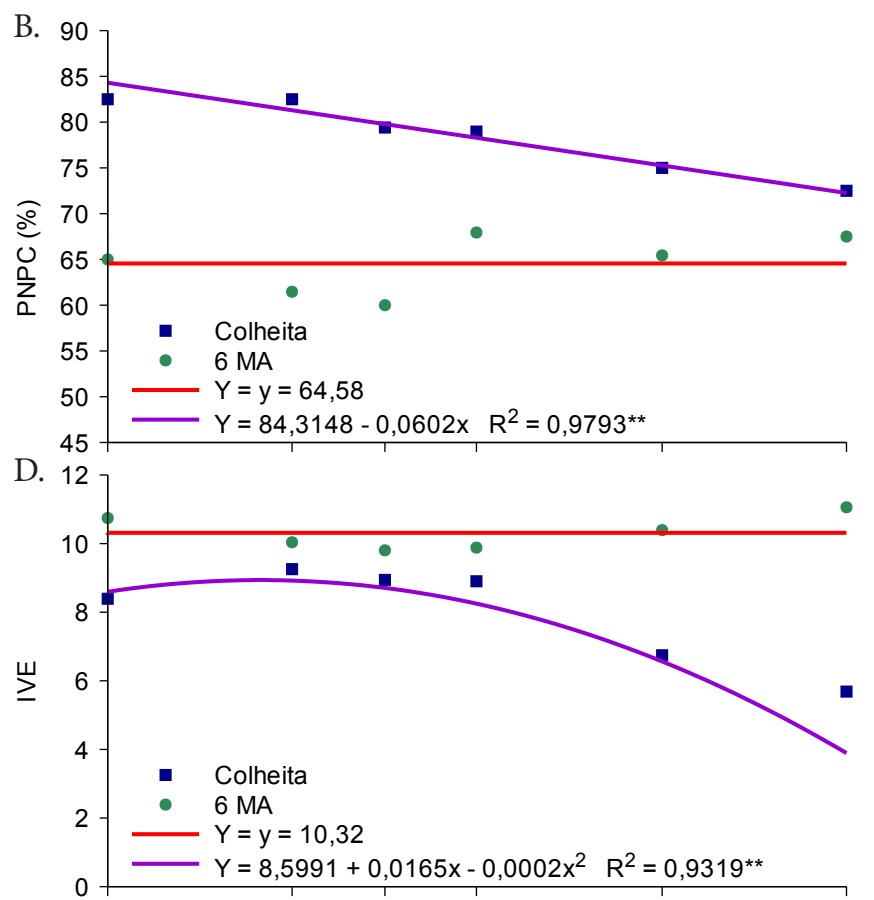


é um indicativo de perda de vigor e qualidade fisiológica no armazenamento. Este fato também foi observado por pesquisadores trabalhando com soja armazenada em diversas condições (Zuchi et al., 2013).

Em relação à percentagem de plântulas normais na primeira contagem de germinação, o aumento da dose de saflufenacil provocou resposta linear do percentual de plântulas normais na primeira contagem (Figura 2B) evidenciando decréscimos em seus valores na avaliação realizada na colheita. Portanto, pode-se inferir, ainda, que a condutividade elétrica apresentou certa relação com o teste da primeira contagem, em que as doses elevadas do dessecante reduziram a percentagem de plântulas normais.

Resultados semelhantes foram encontrados por Colete et al. (2007) quando trabalharam com sementes de soja e verificaram que maiores valores de lixiviação de solutos corresponderam às menores porcentagens de plântulas normais. Após o período de armazenamento ocorreu queda no vigor das sementes sendo que a percentagem de plântulas ficou em torno de $64,58 \%$, não sofrendo alteração da aplicação do produto em pré-colheita.

A percentagem de emergência e o índice de velocidade de emergência sofreram efeitos da interação dos fatores. $\mathrm{Na}$ colheit, as respostas foram superiores em ambas as variáveis independentes da dose do dessecante. Após o período de armazenamento houve redução na percentagem de emergência das plântulas e no IVE, tendo resposta quadrática para doses do dessecante obtendo o ponto máximo quando a dose aplicada foi 65,2 e 50,5 g i.a ha ${ }^{-1}$, respectivamente (Figura 2C e 2D).

Franco et al. (2013) encontraram, avaliando a produção e a qualidade fisiológica de semente de feijão após a aplicação do herbicida diquat, redução da percentagem de emergência e na velocidade apenas em relação à época de aplicação do herbicida e não houve interferência quanto à dose sendo que foram observados valores superiores a 83 e 95 DAS (dias após a semeadura) e inferiores a 87 e 89 DAS, fato que comprova a deterioração das sementes quando as plantas de feijão são dessecadas na sua fase de maturação.

O comprimento de raiz primária de plântula foi afetado pela interação entre épocas e doses de saflufenacil. Na colheita o comprimento de plantas foi maior, independentemente da dose do dessecante. Verificou-se, com o armazenamento, queda no comprimento, além de resposta quadrática para as doses do herbicida sendo que o ponto máximo ocorreu com a dose de 56,5 g i.a ha-1 levando ao maior desenvolvimento inicial da radícula (Figura $2 \mathrm{E}$ ).

O comprimento da parte aérea da plântula sofreu alterações pelos fatores isolados. $\mathrm{O}$ armazenamento reduziu o comprimento de hipocótilo e a resposta dessa variável foi quadrática em relação à dose do dessecante mesmo que, de forma análoga ao comprimento de raiz, a dose que favoreceu o maior desenvolvimento foi de $57 \mathrm{~g}$ i.a ha-1 (Figura 2F). Por outro lado observou-se, quando avaliado o comprimento total de plântula, não apenas efeito da interação época de avaliação mas também doses de aplicação de saflufenacil. Na colheita o comprimento de plântula foi maior, independente da dose e após o armazenamento sofre redução do tamanho e resposta quadrática para a dose do produto similar ao observado para tamanho de raiz e hipocótilo em que a dose que promoveu maior comprimento de plântula foi de $59 \mathrm{~g}$ i.a ha-1 (Figura $2 \mathrm{G})$. Kappes et al. (2012) verificaram que o crescimento e o acúmulo de biomassa das plântulas de feijão foram reduzidos pela aplicação de paraquat em pré-colheita.

Não foi observada variação no teor de água das sementes cujos valores médios se situaram em torno de $12,50 \%$ (b.u.) (Tabela 1). A variação no teor de água ocorre em função do ambiente em que as sementes foram armazenadas tendo relação com as condições de temperatura e de umidade relativa (Juvino et al., 2014).

O percentual de germinação e o número de plântulas normais após o envelhecimento acelerado de sementes foram afetados pela época de avaliação (Tabela 1). Efeitos de dessecantes não afetando a germinação de sementes de feijão foram obtidos por Kappes et al. (2012) e Franco et al. (2013) trabalhando com cultivares do grupo Carioca e realizando a aplicação no estádio R7 do feijoeiro. Os efeitos negativos nessas variáveis (PN e PNEA) ocorreram após o armazenamento das sementes por seis meses quando houve redução no vigor (Tabela 1). O nível de vigor das sementes afeta o estabelecimento da cultura, o desenvolvimento das plantas, a uniformidade da lavoura e a sua produtividade (Toledo et al., 2014).

A percentagem de plântulas anormais no teste de germinação aumentou após os seis meses de armazenamento (Tabela 1). Barbosa et al. (2010) observaram perda de vigor nas sementes de soja durante os seis meses de armazenamento com temperatura de $23^{\circ} \mathrm{C}$ e umidade relativa do ar de 60\%. Cardoso et al. (2012) constataram redução nos valores de primeira contagem da germinação ao longo do armazenamento utilizando sementes de crambe durante nove meses armazenados em diferentes embalagens.

Com relação à biomassa seca de plântula, houve diferença entre as médias apenas em função do armazenamento obtendo-se plântulas com menor acúmulo de massa seca na raiz, hipocótilo e total, após seis meses de armazenamento (Tabela 2).

Com a análise sanitária das sementes de feijão-azuki foram identificados cinco gêneros de fungos, sendo eles: Aspergillus sp., Cladosporium sp., Fusarium sp., Penicillium

Tabela 1. Teor de água (TA) plântulas normais após o envelhecimento acelerado (PNEA), plântulas anormais PA (\%) e plântulas normais na germinação - PN (\%) em sementes de feijão-azuki em função de doses do dessecante saflufenacil aplicado em pré-colheita e avaliado em duas épocas, na colheita (sem armazenamento das sementes) e após armazenamento por seis meses (6 MA)

\begin{tabular}{|c|c|c|c|c|}
\hline \multirow{2}{*}{ Tratamentos } & $\mathrm{TA}^{1 /}$ & PNEA & PA & PN \\
\hline & \% b.u. & \multicolumn{3}{|c|}{$\%$} \\
\hline $0(\mathrm{~g}$ i.a ha-1) & 12,53 & 56,00 & 13,25 & 83,25 \\
\hline 50 (g i.a ha-1) & 12,53 & 60,75 & 12,00 & 85,25 \\
\hline 75 (g i.a ha-1) & 12,29 & 54,25 & 13,25 & 83,00 \\
\hline 100 (g i.a ha-1) & 12,58 & 51,50 & 10,25 & 86,75 \\
\hline 150 (g i.a ha $\left.{ }^{-1}\right)$ & 12,82 & 53,75 & 17,25 & 79,25 \\
\hline $200\left(\mathrm{~g}\right.$ i.a ha $\left.{ }^{-1}\right)$ & 12,37 & 55,50 & 11,00 & 87,25 \\
\hline Colheita & 12,52 & $68,58 \mathrm{a}$ & $5,0 \mathrm{~b}$ & $91,66 \mathrm{a}$ \\
\hline $6 \mathrm{MA}$ & 12,51 & $42,0 \mathrm{~b}$ & $20,66 \mathrm{a}$ & $76,58 \mathrm{~b}$ \\
\hline
\end{tabular}

${ }^{1 / M e ́ d i a s ~ s e g u i d a s ~ d e ~ l e t r a s ~ i g u a i s ~ n a s ~ c o l u n a s ~ s a ̃ o ~ e s t a t i s t i c a m e n t e ~ i g u a i s ~ p e l o ~ t e s t e ~} \mathrm{~F}$ a 0,05 de significância 
Tabela 2. Massa seca hipocótilo (MSH), massa seca raiz (MSR) e massa seca total de plântulas (MST) em sementes de feijão-azuki em função de doses do dessecante saflufenacil aplicado em pré-colheita e avaliado em duas épocas, na colheita (sem armazenamento das sementes) e após armazenamento por seis meses (6 MA)

\begin{tabular}{|c|c|c|c|}
\hline \multirow{2}{*}{ Tratamentos } & $\mathrm{MSH}^{1 /}$ & MSR & MST \\
\hline & \multicolumn{3}{|c|}{ g } \\
\hline 0 (g i.a ha-1) & 0,42 & 0,22 & 0,63 \\
\hline 50 (g i.a ha $\left.^{-1}\right)$ & 0,47 & 0,24 & 0,72 \\
\hline 75 (g i.a ha-1) & 0,49 & 0,30 & 0,78 \\
\hline 100 (g i.a ha-1) & 0,48 & 0,22 & 0,70 \\
\hline 150 (g i.a ha-1) & 0,36 & 0,62 & 0,98 \\
\hline $200\left(\mathrm{~g}\right.$ i.a ha $\left.{ }^{-1}\right)$ & 0,47 & 0,35 & 0,83 \\
\hline Colheita & $0,72 \mathrm{a}$ & $0,53 \mathrm{a}$ & $1,26 \mathrm{a}$ \\
\hline $6 \mathrm{MA}$ & $0,15 b$ & $0,12 \mathrm{~b}$ & $0,29 \mathrm{~b}$ \\
\hline
\end{tabular}

${ }^{1 / M e ́ d i a s ~ s e g u i d a s ~ d e ~ l e t r a s ~ i g u a i s ~ n a s ~ c o l u n a s ~ s a ̃ o ~ e s t a t i s t i c a m e n t e ~ i g u a i s ~ p e l o ~ t e s t e ~} \mathrm{~F} \mathrm{a}$ 0,05 de significância

sp., e Rizhopus sp. Flávio et al. (2014) também relataram que os principais fungos ocorrentes em sorgo em condições de colheita e aos nove meses após armazenamento em condições não controladas, são os citados acima. Considerados fungos de armazenamento, Aspergillus sp. e Penicillium sp. podem, além
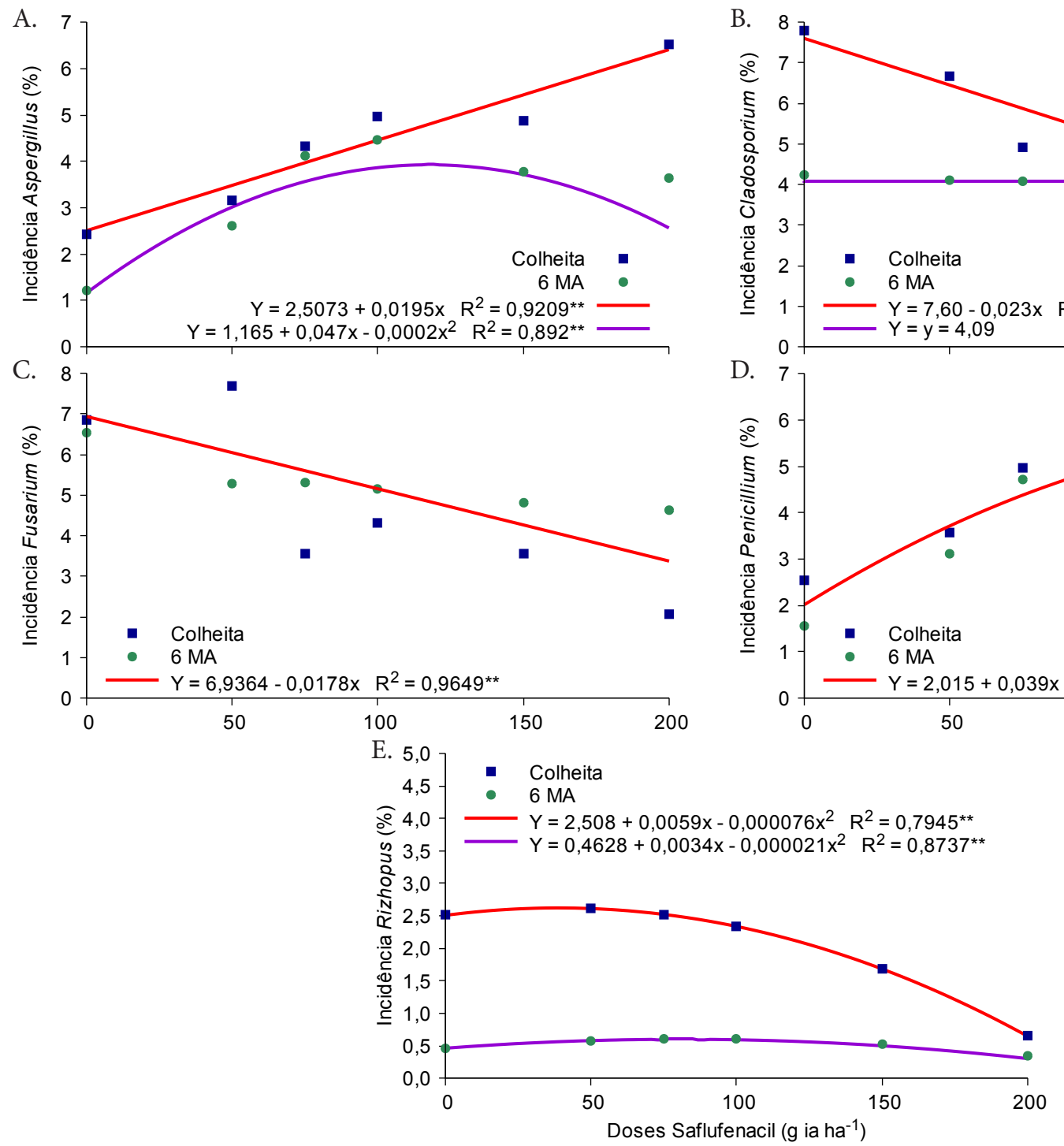

Figura 3. Percentagem de incidência dos fungos: Aspergillus (A), Cladosporium (B), Fusarium (C), Penicillium (D), Rizhopus (E), em sementes de feijão-azuki em função de doses do dessecante saflufenacil aplicado em pré-colheita e avaliado em duas épocas, na colheita (sem armazenamento das sementes) e após armazenamento por seis meses (6 MA)

de deteriorar grãos e sementes, produzir micotoxinas que são tóxicos para humanos, animais e plantas (Riverberi et al., 2010).

Os gêneros de fungos Aspergillus, Cladosporium, Fusarium e Rizhopus sofreram influência da interação das fontes de variação enquanto Penicillium teve influência dos fatores, de forma isolada. A incidência de Aspergillus apresentou comportamento crescente linear em relação às doses do dessecante na colheita e, após seis meses de armazenamento, resposta quadrática com menor incidência do patógeno (Figuras 3A) provavelmente pelo teor de água das sementes e as condições do armazenamento não terem sido favoráveis ao desenvolvimento do mesmo.

Fusarium apresentou, por ser considerado um patógeno de campo, comportamento linear em relação às doses dos dessecantes (Figura 3C) cuja ocorrência é devida à rápida queda do teor de água nas plantas, dificultando a sobrevivência desse fungo. Cladosporium, Penicillium e Rizhopus (Figuras $3 \mathrm{~B}, 3 \mathrm{D}$ e $3 \mathrm{E}$ ) também sofreram queda na incidência após os seis meses de armazenamento demonstrando que as condições em que as sementes foram armazenadas não favoreceram o desenvolvimento de fungos.
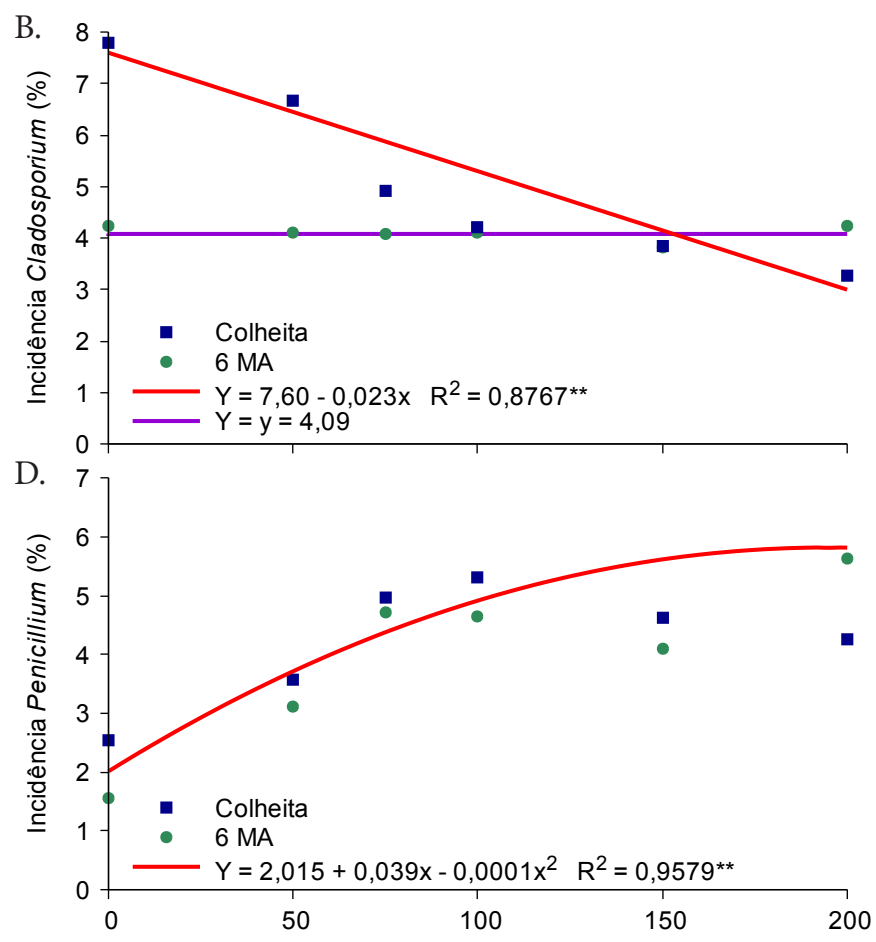


\section{Conclusões}

1. O herbicida saflufenacil pode ser utilizado para dessecação de campo de produção de feijão-azuki até a dose de $65 \mathrm{~g}$.a ha ${ }^{-1}$ sem prejudicar a qualidade fisiológica das sementes.

2. O armazenamento por seis meses em ambiente natural afeta a qualidade fisiológica de sementes de feijão-azuki.

3. A dessecação em pré-colheita e o armazenamento reduzem a infestação Cladosporium, Fusarium, e Rizhopus nas sementes de feijão-azuki, que são patógenos considerados de campo.

\section{Literatura Citada}

Almeida, D. P.; Resende, O.; Costa, L. M.; Mendes, U. C. Higroscopicidade das sementes de feijão adzuki. Científica, v.41, p.130-137, 2013.

Barbosa, C. Z. R.; Smiderle, O. J.; Alves, J. M. A.; Vilarinho, A. A.; Sediyama, T. Qualidade de sementes de soja BRS Tracajá, colhidas em Roraima em função do tamanho no armazenamento. Revista Ciência Agronômica, v.41, p.73-80, 2010.

Brasil. Ministério da Agricultura, Pecuária e Abastecimento. Regras para análise de sementes. Ministério da Agricultura, Pecuária e Abastecimento. Secretaria de Defesa Agropecuária. Brasília: Mapa/ACS, 2009. 395p.

Cardoso, R. B.; Binotti, F. F. S.; Cardoso, E. D. Potencial fisiológico de sementes de crambe em função de embalagens e armazenamento. Pesquisa Agropecuária Tropical, v.42, p.272-278, 2012. http:// dx.doi.org/10.1590/S1983-40632012000300006

Colete, J. C. F.; Vieira, R. D.; Panobianco, M.; Dutra, A. S. Condutividade elétrica da solução de embebição de sementes e emergência de plântulas de soja. Científica, v.35, p.10-16, 2007.

Flávio, N. S. D. S.; Sales, N. L. P.; Aquino, C. F.; Soares, E. P. S.; Aquino, L. F. S.; Catão, H. C. R. M. Qualidade sanitária e fisiológica de sementes de sorgo tratadas com extratos aquosos e óleos essenciais. Semina: Ciências Agrárias, v.35, p.7-20, 2014. http:// dx.doi.org/10.5433/1679-0359.2014v35n1p7

Franco, M. H. R.; Nery, M. C.; França, A. C.; Oliveira, M. C.; Franco, G. N.; Lemos, V. T. Produção e qualidade fisiológica de semente de feijão após aplicação do herbicida diquat. Semina: Ciências Agrárias, v.34, p.1707-1714, 2013. http://dx.doi.org/ 10.5433/1679-0359.2013v34n4p1707
Grossmann, K.; Hutzeler, J.; Caspar, G.; Kwiatkowski, J.; Brommer, C. L. Saflufenacil: Biokinetic properties and mechanism of selectivity of a new protoporphyrinogen IX oxidade inhibiting herbicide. Weed Science, v.59, p.290-298, 2011. http://dx.doi.org/10.1614/ WS-D-10-00179.1

Juvino, A. N. K.; Resende, O.; Costa, L. M.; Sales, J. F. Vigor da cultivar BMX Potência RR de soja durante o beneficiamento e períodos de armazenamento. Revista Brasileira de Engenharia Agrícola e Ambiental, v.18, p.844-850, 2014. http://dx.doi.org/10.1590/18071929/agriambi.v18n08p844-850

Kappes, C.; Arf, O.; Ferreira, J. P.; Portugal, J. R.; Alcalde, A. M.; Arf, M. V.; Vilela, R. G. Qualidade fisiológica de sementes e crescimento de plântulas de feijoeiro, em função de aplicações de paraquat em pré-colheita. Pesquisa Agropecuária Tropical, v.42, p.9-18, 2012. http://dx.doi.org/10.1590/S198340632012000100002

Neergaard, P. Seed pathology. 2.ed. London: MacMillan Press, 1979. 2v. 1191p.

Riverberi, M.; Ricelli, A.; Zlalic, S. Fabbri, A. A.; Fanelli, C. Natural functions of mycotoxins and control of their biosynthesis in fungi. Applied Microbiology and Biotechnology, v.87, p.899-911, 2010. http://dx.doi.org/10.1007/s00253-010-2657-5

Silva, M. M.; Souza, H. R. T.; David, A. M. S. S.; Santos, L. M.; Silva, R. F.; Amaro, H. T. R. Qualidade fisiológica e armazenamento de sementes de feijão-comum produzidas no norte de Minas Gerais. Revista Agro@mbiente, v.8, p.97-103, 2014.

Toledo, M. Z.; Ishizuka, M. S.; Cavariani, C.; França Neto, J. B.; Picoli, L. B. Dessecação em pré-colheita com glifosato e qualidade de sementes armazenadas de soja. Semina: Ciências Agrárias, v.35, p.765-774, 2014. http://dx.doi.org/10.5433/16790359.2014v35n2p765

Vieira, R. D.; Krzyzanowiski, F. C. Teste de condutividade elétrica. In: Krzyzanowiski, F. C.; Vieira, R. D.; França Neto, J. B. (ed). Vigor de sementes: Conceitos e testes. Londrina: ABRATES, 1999. cap.4, p.1-26.

Zuchi, J.; França Neto, J. B.; Sediyama, C. S.; Lacerda Filho, A. F.; Reis, M. S. Physiological quality of dynamically cooled and stored soybean seeds. Journal of Seed Science, v.35, p.353-360, 2013. http://dx.doi.org/10.1590/S2317-15372013000300012 